\title{
The Relationship between Perfectionism and Language Proficiency in Intermediate, Upper Intermediate, and Advanced Students of Kerman Institutes
}

\author{
Mina Rastegar, Massoud Khabir, Ehsan Mehrabi Kermani \\ Shahid Bahonar University, Kerman, Iran \\ Email: Massoud.khabir@gmail.com
}

How to cite this paper: Rastegar, M., Khabir, M., \& Mehrabi Kermani, E. (2017). The Relationship between Perfectionism and Language Proficiency in Intermediate, Upper Intermediate, and Advanced Students of Kerman Institutes. Open Journal of Modern Linguistics, 7, 142-150.

https://doi.org/10.4236/ojml.2017.72011

Received: February 19, 2017

Accepted: April 17, 2017

Published: April 20, 2017

Copyright $\odot 2017$ by authors and Scientific Research Publishing Inc. This work is licensed under the Creative Commons Attribution International License (CC BY 4.0).

http://creativecommons.org/licenses/by/4.0/

\begin{abstract}
Language proficiency is the ultimate goal of English as a Foreign Language studies. The present study attempted to explore any significant relationships between perfectionism and its dimensions as a whole and language proficiency of students of Kerman institutes. A number of 98 participants studying English at intermediate, upper-intermediate, and advanced levels as a foreign language at Kerman institutes took part in this study. To obtain the required data, the following instruments were administered: Multidimensional Perfectionism Scale (Frost \& Marten, 1990) to measure participants' level of perfectionism and its dimensions and the short version of Michigan Test (Briggs, Dobson, Rohlick, Spann, \& Strom, 1997) to measure the participants' level of language proficiency. The SPSS results depicted that there was a significant positive relationship between the construct perfectionism and language proficiency.
\end{abstract}

\section{Keywords}

Perfectionism, Language Proficiency, English as a Foreign Language

\section{Introduction}

Nowadays, a great number of people step into the seemingly unpaved road of learning a new language, which will connect them not only to the outer world but also to different countries, people, and their cultures. Research has shown that language seekers should not be looked at just simply, but modularly with several variables involved. Moreover, not all language seekers will proficiently succeed in their quest. Foreign language learners send up with different de- 
grees of success in their attempt to master the language. According to Larsen-Freeman (1991), various personality traits have been believed to facilitate or inhibit L2 learning. Among these personality traits which may be influencing the degree of L2 learners' final success is perfectionism which can be implored. Perfectionism may have a positive, negative, or no relationship with language proficiency of the learners which is the aim of this research to determine.

\section{Conceptions}

There are two conceptions in this research whose relationships are being sought systematically, statistically, and descriptively. The aforementioned conceptions namely, perfectionism and language proficiency, are elaborated on below.

\subsection{Perfectionism}

Perfectionism is a personality trait which is commonly characterized by striving for flawlessness, the setting of excessively high standards for performance, and tendencies towards self-criticalness. Among affective factors, perfectionism and its dimensions such as Concern over Mistakes (CM), Personal Standards (PS), Doubts about Actions (DA), Organization (O), Parental Criticisms (PC) and Parental Expectations (PE) are salient constructs in the field of psychology (Frost \& Marten, 1990).

Six dimensions of perfectionism have been defined as follows: According to Frost and Marten (1990), CM is defined as "being so worried about mistakes and reacting negatively to them, avoiding mistakes for avoiding failure, and believing that respect from others is compromised by failure" (p. 563). PS is conceptualized as a demand for high standards (Hamachek, 1978). Frost, Marten, Lahart and Rosenblate (1990) elaborated on PS as "Setting and striving for high standards were not in itself deleterious and pathological, the tendency to overly criticize and evaluate one's own behavior were associated with psychological problems with regard to perfectionism" (p. 461). Frost et al. (1990) argued that there is an inadequate and unsatisfactory sense for task completion reflected in DA dimension. Doubts about the quality of actions that are performed bring a feeling of dissatisfaction for a person when a task is completed (p. 451). According to Hollender (1965), "perfectionists are too concerned about details and they pay too much attention to orderliness and regularity" (p. 98). This emphasis is associated with challenge of achieving standards for self-evaluation of performance and an exaggerated need for order (Frost et al., 1990). Frost et al. (1990) defined $\mathrm{O}$ as an exaggerated emphasis on order, precision and organization, $\mathrm{PC}$ as the belief that parents are overly critical when their standards are not meet and feelings derived from falling short of their expectations, and PE as the belief that one could never meet his/her parents' excessively high standards. According to Frost et al. (1990), the first four dimensions are related to self-evaluative aspects of perfectionism, whereas the last two components of perfectionism focus on socially evaluative reactions to themself. 
The negative impact of excessive perfectionistic view on humans has been well established and implored in previous studies (Chang \& Edward, 2000). However, there has not been a lot done on its positive influence on foreign language learning and the significance it bears.

\subsection{Language Proficiency}

Language proficiency or linguistic proficiency is the ability of an individual to speak or perform in an acquired language. Fluency and language competence are generally recognized as being representatives of different levels of language proficiency. In predominant frameworks, proficient speakers demonstrate both accuracy and fluency and use a variety of discourse strategies. Thus, native speakers of a language can be fluent without being considered proficient.

According to Bachman (1990), Language proficiency (LP) is defined as "the general knowledge, competence, or ability in the use of a language, irrespective of how, where, or under what conditions it has been acquired" (p. 32).

\section{Objectives of the Study}

There are a lot of researches on perfectionism and also on language proficiency. However, the number of studies on the relationship between perfectionism as a whole and language proficiency can be counted. Therefore, this study attempted to hold a holistic view towards perfectionism. It also approached general proficiency of students as a whole and investigated the underlying relationship between perfectionism and general proficiency of English learners, keeping the null hypothesis that there is no relationship.

\section{Significance of the Study}

Provided that results of the study show that the relationship between perfectionism and general proficiency is positive, therefore, those students who are perfectionist will be more proficient. In case of a negative correlation, the proficiency rises with a rise in perfectionism as well. However, supposing there would be some participants with a non-perfectionistic attitude, the proficiency would be to a lower level compared to positive and negative perfectionists.

\section{Users of the Study}

With a viewpoint towards the 6 dimensions of perfectionism, their relationship with general language proficiency, and also the final relationship (positive, negative, or no relationship), this research may be of importance to parents, EFL teachers, EFL learners and anyone who is somehow involved or interested in EFL affair.

\section{Research Questions:}

1) Are there any significant relationships between perfectionism and language proficiency of English learners of Kerman institutes?

2) Are there any significant differences between males and females in their language proficiency and perfectionism? 


\section{Literature Review}

In a study, Pourmohammadi (2012) attempted to explore the relationship between perfectionism and its four dimensions (Concern over Mistakes, Personal Standards, Doubts about Actions, Organization) and Language Proficiency (LP) among Iranian EFL Learners. The results revealed that there was a significant positive relationship between the construct Perfectionism and LP. In respect to dimensions of perfectionism, there were significant positive relationships between the following pairs: Personal Standards and LP and Organization and LP. However, there were negative non-significant relationships between the following pairs: Concern over Mistakes and LP, and Doubts about Actions and LP. A Multiple Regression with LP as criteria and perfectionism subscales as predictors was also conducted. Analysis showed that organization $(\beta=0.34)$ and personal standards $(\beta=0.23)$ had the highest relationship with language proficiency. Concern over mistakes and doubt about actions did not explain language proficiency.

One study carried out by Pishghadam and Akhondpoor (2011) tried to examine the role of learners' perfectionism in foreign language learning success, academic achievement, and learner anxiety. In their study, they made use of a sample of 300 junior and senior students of English in Mashhad universities. Students' grades of four skills (reading, speaking, listening, and writing) and GPA were obtained through the questionnaires. The results of the correlational analysis indicated a negative significant relationship between skills of reading, speaking, listening, GPA, and perfectionism. The results did not confirm the researchers' hypothesis with regard to the relationships between age, gender, and learner perfectionism. The findings of their study showed how perfectionistic tendencies in language learners were associated with low academic achievement and poor performance in language skills.

Witcher, Alexander, Onwuegbuzie, Collins, and Witcher (2007) investigated the relationship between the three dimensions of perfectionism and achievement in a graduate-level research methodology course. Achievement, which involved students' knowledge of research concepts, methodologies, and applications, was measured individually in all sections via comprehensive written midterm and final examinations. A canonical correlation analysis revealed that graduate students with relatively high levels of self-oriented perfectionism and other-oriented perfectionism tended to have the highest levels of achievement in the class, with socially prescribed perfectionism serving as a suppressor variable. Self-oriented perfectionism was the best predictor of performance, highlighting the relative importance of this dimension of perfectionism in the context of learning in research methodology courses.

\section{Method}

\subsection{Participants and Setting}

The participants taking part in this research were intermediate, upper-interme- 
diate, and advanced EFL learners. They were randomly selected using probability sampling to be from among three branches of Language House Institute. All of these learners were proficient speakers of Persian. The total number of participants was 98 of which 41 were male and 57 were female. The classes consisted of both male and female students.

\subsection{Instrumentation}

The following instruments were utilized to measure the variables of the study:

Multidimensional Perfectionism Scale (Frost et al., 1990)

Michigan Test (Briggs et al., 1997)

\subsubsection{Frost Multidimensional Perfectionism Scale (MPS)}

The MPS, designed by Frost et al. (1990), assesses several dimensions of perfectionism. A 5-point Likert scale containing 35 items was used throughout MPS. The MPS items ranged from strongly disagree to strongly agree. The MPS has 6 subscales, each of which tries to evaluate one of learners' points of view in perfectionism. These 35 items are designed to measure six dimensions of perfectionism: CM (items 9, 10, 13, 14, 18, 21, 23, 25, 34), PS (items 4, 6, 12, 16 19, 24, 30), DA (items 17, 28, 32, 33), O (items 2, 7, 8, 27, 29, 31), PC (items $3,5,22,35$ ), and $\mathrm{PE}$ (items 1, 11, 15, 20, 26). The participants were required to choose one of the following alternatives: Strongly Agree (SA), Agree (A), Undecided (U), Disagree (D), or Strongly Disagree (SD). For each item, the highest degree of perfectionism receives five points and the lowest, one point. The range of the score for this scale is from 26 to 130. Participants' higher scores indicate stronger perfectionism level and lower scores manifest lower perfectionist tendency. To date, a number of studies investigated the psychometric proprieties of MPS, demonstrating that the scale has a high internal consistency (both for the total score and for each subscale) and acceptable levels of discriminant and convergent validity. The original version revealed good reliability (alpha: scale $=0.90$; subscales: $0.77-0.93$ ).

\subsubsection{Michigan Test of English Language Proficiency}

English language ability is tested in these areas on the Michigan Test: reading, writing, grammar, vocabulary, and listening. Speaking is an optional part of the Michigan Battery. The Michigan Test of English Language Proficiency consists of 100 multiple choice questions: 40 English Grammar questions, 40 Vocabulary questions, and 20 reading Comprehension questions. The short version of Language Proficiency (LP) Test adopted from the Examination for the Certificate of Proficiency in English (ECPE) of Michigan University (Briggs et al., 1997) was used for measuring the level of the participants' language proficiency in this study. It consists of 35 multiple choice items. The participants need to choose the best answer for each item. It starts with a cloze test with 10 blanks. The second part checks the students' knowledge in syntax by 10 grammatical questions. Then the students continue by answering the vocabulary part of the test. In vocabulary part they should choose the best 
words that fit in the blanks. This part has also 10 items. The last part is about the reading comprehension. The participants read a passage and then they have 5 questions on the content of the passage. For each correct answer they will get a point. Participants' scores would range from 0 to 35 .

\section{Data Collection}

All the data needed for analysis and interpretation by a statistician were collected by means of MPS and the Michigan Test of English Language Proficiency. The MPS was administered to the participants during the class time. The participants were asked to go over the MPS with no time limit. The MPS questionnaires were then collected by the researcher for data analysis. Likewise, the Michigan Test of English Language Proficiency was given to the same groups of students at the end of the term. A full class hour was allocated for the test to be answered. The participants were told that the scores would be considered confidential and that they would not be accounted as their final exam scores. It was also mentioned that the Michigan test was being administered just for the sake of research.

\section{Data Analysis Procedure}

To carry out the statistical procedures of this research project, two sets of scores were utilized for each of the participants. The first set represented the degree of participants' perfectionism and the other set reflected their level of general English language proficiency. To obtain descriptive statistics, a statistician using SPSS (V. 23) analyzed and interpreted the gathered data. The results of the data analysis are presented as follows.

\section{Results}

\subsection{Descriptive Statistics}

As shown in Table 1 there were 98 participants in this research. The two variables, namely Perfectionism and General Proficiency, were measured by MPS scale and Michigan Test, respectively. Perfectionism scores were extracted carefully and mentioned descriptively here as well as the scores for the Michigan Test.

\subsection{Gender Frequency}

The frequency of participants in terms of gender is reflected in Table 2. Male participants were 41 (41.8\%), whereas the number of female participants was 57 (58.2).

\subsection{Perfectionism in Relation with LP}

In order to investigate perfectionism in relation with Language Proficiency, Pearson

Table 1. Descriptive statistics of variables.

\begin{tabular}{cccccccc}
\hline & N & Range & Min & Max & Mean & SD & V \\
\hline Perfectionism & 98 & 81 & 58 & 139 & 106.51 & 22.80 & 519.92 \\
LP & 98 & 16 & 16 & 32 & 26.62 & 4.05 & 16.44 \\
\hline
\end{tabular}


Table 2. Gender: frequency of males and females.

\begin{tabular}{cccccc}
\hline & & Frequency & Percent & Valid Percent & Cumulative Percent \\
\hline \multirow{3}{*}{ Valid } & male & 41 & 41.8 & 41.8 & 41.8 \\
& female & 57 & 58.2 & 58.2 & 100.0 \\
& Total & 98 & 100.0 & 100.0 & \\
\hline
\end{tabular}

Table 3. Correlation between perfectionism and general proficiency.

\begin{tabular}{cccc}
\hline & & Perfectionism & Language Proficiency \\
\hline \multirow{2}{*}{ Perfectionism } & Pearson Correlation & 1 & $0.792^{* *}$ \\
& Sig. (2-tailed) & & 0.000 \\
$\mathrm{~N}$ & 98 & 98 \\
\hline
\end{tabular}

${ }^{*}$ Correlation is significant at the 0.01 level (2-tailed).

Table 4. Perfectionism frequency of participants.

\begin{tabular}{cccccc}
\hline & & Frequency & Percent & Valid Percent & Cumulative Percent \\
\hline \multirow{2}{*}{ Valid } & PN & 24 & 24.5 & 24.5 & 24.5 \\
& P- & 32 & 32.7 & 32.7 & 57.1 \\
& P+ & 42 & 42.9 & 42.9 & 100.0 \\
& Total & 98 & 100.0 & 100.0 & \\
\hline
\end{tabular}

Correlation was conducted. As indicated in Table 3, since $p$-value is smaller than alpha level of $0.05(p=0.000)$, it is concluded that there is a significant relationship between EFL learners' Perfectionism and their Language Proficiency ( $\mathrm{r}$ $=0.79$ ). The reported $\mathrm{r}$ shows that the relationship is a positive one.

\subsection{Perfectionism Frequency of Participants}

The information in Table 4 suggests that the number of participants of both genders altogether with a negative attitude towards perfectionism was 32 (32.7\%), whereas positive perfectionists were 42 (42.9\%). However, the number of Non-Perfectionists was 24 (24.5\%).

\subsection{Perfectionism and Language Proficiency}

In order to investigate Language Proficiency and Perfectionism a One-Way ANOVA analysis was run. As shown in Table 5, since p-value is less than $\alpha=$ 0.05 , therefore there is a significant difference among different levels of positive, negative, and null perfectionism. Comparing the means $(\mathrm{Pn}=20.75, \mathrm{P}-=28.75$, $\mathrm{P}+=28.35)$, it is concluded that non-perfectionists $(\mathrm{Pn})$ had a lower proficiency scores compared with positive $(\mathrm{P}+)$ and negative $(\mathrm{P}-)$ perfectionists. Therefore, $\mathrm{P}+$ and $\mathrm{P}-$ both can be considered as perfectionists yet with different approaches. There was not a significant difference between $\mathrm{P}+$ and $\mathrm{P}-$ participants regarding LP scores. 
Table 5. Perfectionism and language proficiency.

\begin{tabular}{ccccccc}
\hline & N & Mean & S D & F & df & P \\
\hline Pn & 24 & 20.75 & 3.61 & & B $=2$ & \\
P- & 32 & 28.75 & 1.64 & 105.206 & W $=95$ & .000 \\
P+ & 42 & 28.35 & 1.65 & & $\mathrm{~T}=97$ & \\
Total & 98 & 26.62 & 4.05 & & & \\
\hline
\end{tabular}

Table 6. Perfectionism regarding gender frequency.

\begin{tabular}{cccccc}
\hline & Gender & N & Mean & SD & SD error mean \\
\hline \multirow{2}{*}{ Perfectionism } & Male & 41 & 110.48 & 20.55 & 3.21 \\
& Female & 57 & 103.64 & 25.05 & 3.18 \\
\hline
\end{tabular}

\subsection{Group Statistics}

The information in Table 6 reflects that perfectionism in males and females does not show any significance difference.

\section{Discussion}

The findings of this study try to answer the two research questions which sought to find whether there are any significant relationships between Perfectionism and Language Proficiency (LP) regarding gender.

Based on the obtained $p$-value which is lower than the alpha level of 0.05 ( $p=$ $0.000)$, the relationship between Perfectionism and LP is a significant one. Therefore, the findings of this study are in agreement with what Pourmohammadi (2012) had come to. In both studies the researchers found a positive relationship between Perfectionism and LP. Although Pourmohammadi (2012) shed light on the relationship between four aforementioned dimensions of Perfectionism and LP, this research holds a holistic approach of Perfectionism and Language Proficiency.

Another study carried out by Pishghadam and Akhondpoor (2011), came by a reverse result compared to the results of this study. In their research, Pishghadam and Akhondpoor found Perfectionism and LP (measured according to participants' reading, speaking, listening, and writing abilities) to be in a negative correlational relationship with each other.

Parallel with the findings of this research, was the findings which Witcher et al., came to. Their research confirmed that Perfectionism and LP had a high positive relationship with each other.

\section{Limitations of the Study}

During the course of research, the researcher faced some limitations. First, it was a hard work to have all the participants take part in the research and answer both scales of which was long. Second, since the topic of this study is new, there has not been many works done on it. Therefore, the researcher could not get his hand on a lot of relevant literature. 


\section{Conclusion}

This study attempted to find any relationships between perfectionism and Language Proficiency. Perfectionism was looked at as a whole. The findings of this study show that $p$-value is lower than the alpha level of $0.05(p=0.000)$. This, in turn, shows that there is a significant relationship between perfectionism and LP. The one-way ANOVA conducted categorizes the participants as $\mathrm{P}+, \mathrm{P}-$, and $\mathrm{Pn}$. Regarding participants' perfectionism levels and their scores of LP, there is not a significant difference between $\mathrm{P}+$ and $\mathrm{P}-$. That is, both $\mathrm{P}+$ and $\mathrm{P}-$ are perfectionists of some kind. On the other hand, there is a difference between both $\mathrm{P}+$ and $\mathrm{P}-$ and $\mathrm{Pn}$. In other words, the more positively or negatively perfectionistic the students are, the more proficient they will be. $\mathrm{P}+$ learners try to master in their learning path by being the best whereas $\mathrm{P}-$ ones try to be perfect by not doing wrong which stresses them out. Whereas, the more non perfectionist they are, the less proficient will be. In terms of gender differences, none was observed.

\section{References}

Bachman, L. F. (1990). Functional Considerations in Language Testing (3rd ed.). Oxford: Oxford University Press.

Briggs, S., Dobson, B., Rohlick, Th., Spann, M., \& Strom, E. (1997). Examination for the Certificate of Proficiency in English, 4-7.

Chang, E. C. (2000). Perfectionism as a Predictor of Positive and Negative Psychological Outcomes: Examining a Mediation Model in Younger and Older Adults. Journal of Counseling Psychology, 47, 18-26. https://doi.org/10.1037/0022-0167.47.1.18

Frost, R. O., \& Marten, P. A. (1990). Perfectionism and Evaluative Threat. Cognitive Therapy and Research, 14, 559-572. https://doi.org/10.1007/BF01173364

Frost, R. O., Marten, P., Lahart, C. M., \& Rosenblate, R. (1990). The Dimensions of Perfectionism. Cognitive Therapy and Research, 14, 449-468. https://doi.org/10.1007/BF01172967

Hamachek, D. E. (1978). Psychodynamics of Normal and Neurotic Perfectionism. Psychology, 15, 27-33.

Hollender, M. H. (1965). Perfectionism. Comprehensive Psychiatry, 6, 94-103.

Larsen-Freeman, D. (1991). Second Language Acquisition Research: Staking out the Territory. TESOL Quarterly, 25, 315-351. https://doi.org/10.2307/3587466

Pishghadam, R., \& Akhondpoor, F. (2011). Learner Perfectionism and Its Role in Foreign Language Learning Success, Academic Achievement, and Learner Anxiety. Journal of Language Teaching and Research, 2, 432-440. https://doi.org/10.4304/jltr.2.2.432-440

Pourmohammadi, E. (2012). The Relationship between Perfectionism and Language Proficiency of Iranian EFL Learners. Unpublished Master's Thesis, Kerman: Shahid Bahonar University.

Witcher, L. A., Alexander, E. S., Onwuegbuzie, A. J., Collins, K. M. T., \& Witcher, A. E. (2007). The Relationship between Psychology Students' Levels of Perfectionism and Achievement in a Graduate-Level Research Methodology Course. Personality and Individual Differences, 43, 1396-1405. 